\title{
Atorvastatin ameliorates endothelium-specific insulin resistance induced by high glucose combined with high insulin
}

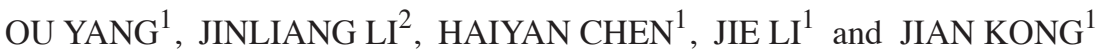 \\ ${ }^{1}$ Department of Cadre Ward, First Hospital, Jilin University, Changchun, Jilin 130021; ${ }^{2}$ Department of Cardiology, \\ Heilongjiang Provincial Hospital, Harbin, Heilongjiang 150001, P.R. China
}

Received August 7, 2015; Accepted June 15, 2016

DOI: $10.3892 / \mathrm{mmr} .2016 .5564$

\begin{abstract}
The aim of the present study was to establish an endothelial cell model of endothelium-specific insulin resistance to evaluate the effect of atorvastatin on insulin resistance-associated endothelial dysfunction and to identify the potential pathway responsible for its action. Cultured human umbilical vein endothelial cells (HUVECs) were pretreated with different concentrations of glucose with, or without, $10^{-5} \mathrm{M}$ insulin for $24 \mathrm{~h}$, following which the cells were treated with atorvastatin. The tyrosine phosphorylation of insulin receptor (IR) and insulin receptor substrate-1 (IRS-1), the production of nitric oxide (NO), the activity and phosphorylation level of endothelial NO synthase (eNOS) on serine1177, and the mRNA levels of endothelin-1 (ET-1) were assessed during the experimental procedure. Treatment of the HUVECs with $30 \mathrm{mM}$ glucose and $10^{-5} \mathrm{M}$ insulin for $24 \mathrm{~h}$ impaired insulin signaling, with reductions in the tyrosine phosphorylation of IR and protein expression of IRS-1 by almost 75 and 65\%, respectively. This, in turn, decreased the activity and phosphorylation of eNOS on serine1177, and reduced the production of NO by almost $80 \%$. By contrast, the mRNA levels of ET-1 were upregulated. All these changes were ameliorated by atorvastatin. Taken together, these results demonstrated that high concentrations of glucose and insulin impaired insulin signaling leading to endothelial dysfunction, and that atorvastatin ameliorated these changes, acting primarily through the phosphatidylinositol 3-kinase/Akt/eNOS signaling pathway.
\end{abstract}

Correspondence to: Professor Jian Kong or Professor Jie Li, Department of Cadre Ward, First Hospital, Jilin University, 71 Xinmin Avenue, Changchun, Jilin 130021, P.R. China

E-mail: kongjian-2005@163.com

E-mail: yabianwanghai@163.com

Key words: cardiovascular disease, insulin resistance, endothelial dysfunction, nitric oxide, atorvastatin

\section{Introduction}

Cardiovascular disease, particularly, coronary artery disease, is a leading contributor to mortality rates worldwide. Compelling evidence suggests that endothelial dysfunction, which results from the reduction of nitric oxide (NO) and the impairment of NO bioavailability, is a key early event in the pathogenesis of atherosclerosis and an important predictor of cardiovascular disease (1-4).

Insulin resistance, the early stage of type 2 diabetes, is not only accompanied by glucose and lipid metabolism disorder, but is also associated with endothelial dysfunction (5). A number of studies have suggested that insulin resistance is one of the independent risk factors for the progression of cardiovascular diseases $(6,7)$.

The reciprocal association between insulin resistance and endothelial dysfunction in the development of diabetes and cardiovascular disease has been suggested in animal studies $(8,9)$. Notably, studies have suggested that the impairment of insulin signaling results in the reduced production of NO in an animal model $(10,11)$. In addition, animal and clinical studies have demonstrated that endothelial cells exhibit dysfunction in response to high glucose concentrations $(12,13)$, or prolonged modest hyperinsulinemia $(14,15)$. However, in vivo, several complicated factors, including individual differences in experimental and insulin receptor sensitivity, affect endothelial dysfunction; thus a reproducible and highly stable endothelial cell model of endothelium-specific insulin resistance is essential to examine the specific insulin signaling associated with endothelial dysfunction.

Atorvastatin, a vessel protective drug, have been confirmed to reduce cardiovascular events in patients by protecting endothelial function, in addition to decreasing levels of cholesterol (16). This drug has pleiotropic effects, including the upregulation and activation of endothelial NO synthase (eNOS), which in turn causes an increase in the production of $\mathrm{NO}$, and reduces oxidative stress and vascular inflammation $(17,18)$. Phosphatidylinositol 3-kinase (PI3K) is one of the most well-characterized downstream effectors of insulin receptor substrate-1 (IRS-1) proteins (19). In vivo studies have suggested that atorvastatin improves endothelial function via the phosphatidylinositol 3-kinase (PI3K)/Akt/eNOS pathway (20-22). 
In the present study, an endothelial cell model of endothelium-specific insulin resistance was established, which was induced by high concentrations of glucose in combination with high concentrations of insulin. Subsequently, the cell model was treated with atorvastatin to evaluate its effect on insulin resistance-associated endothelial dysfunction and to identify the potential pathway responsible for its action.

\section{Materials and methods}

Cell culture. Human umbilical vein endothelial cells (HUVECs) (23), provided by the Department of Pathology, Jilin University (Jilin, China), were purchases from Cobioer Biosciences (Nanjing, China). The cells were maintained at $37^{\circ} \mathrm{C}$ in humidified air $\left(5 \% \mathrm{CO}_{2}\right)$ and cultured in serum-free Dulbecco's modified Eagle's medium (DMEM; GE Healthcare Life Science HyClone Laboratories, Logan, UT, USA) with 5 mM D-glucose (GE Healthcare Life Science HyClone Laboratories), 4 mM L-glutamine, and $20 \%$ fetal bovine serum (GE Healthcare Life Science HyClone Laboratories).

Treatment of HUVECs with high glucose and high insulin concentrations to impair insulin signaling. HUVECs $\left(10^{5} / \mathrm{ml}\right)$ were incubated in culture medium containing 5,15 or $30 \mathrm{mM}$ $\mathrm{D}$-glucose. The cells were maintained at $37^{\circ} \mathrm{C}$ in humidified air $\left(5 \% \mathrm{CO}_{2}\right)$ with or without $10^{-5} \mathrm{M}$ insulin for $24 \mathrm{~h}$. The medium was then discarded, the cells were washed twice with phosphate-buffered saline (PBS), and were then incubated for $6 \mathrm{~h}$ following the addition of $10^{-5} \mathrm{M}$ insulin at $37^{\circ} \mathrm{C}$ with $5 \%$ $\mathrm{CO}_{2}$.

Treatment with atorvastatin. HUVECs $\left(10^{6} / \mathrm{ml}\right)$ cultured in normal culture medium (Nor vec) and HUVECs pretreated with $30 \mathrm{mM}$ glucose and $10^{-5} \mathrm{M}$ insulin for $24 \mathrm{~h}$ at $37^{\circ} \mathrm{C}$ with $5 \% \mathrm{CO}_{2}$, defined as insulin-resistant HUVECs (IR vec), were treated with varying concentrations of atorvastatin $(0$, $10^{-6}, 10^{-5}$ and $10^{-4} \mathrm{M}$ ) for $24 \mathrm{~h}$ or were treated with $10^{-4} \mathrm{M}$ atorvastatin for $0,3,6,9,12,15,18,21$ and $24 \mathrm{~h}$ at $37^{\circ} \mathrm{C}$ with $5 \% \mathrm{CO}_{2}$.

Treatment with LY29004, an inhibitor of PI3K. The Nor vec and IR vec cells $\left(10^{6} / \mathrm{ml}\right)$ were treated with PBS (control), $10^{-4} \mathrm{M}$ atorvastatin only, $25 \mu \mathrm{M}$ LY29004 (Merck Millipore, Darmstadt, Germany) alone or with a combination of $10^{-4} \mathrm{M}$ atorvastatin and $25 \mu \mathrm{M} \mathrm{LY} 29004$ for $24 \mathrm{~h}$ at $37^{\circ} \mathrm{C}$ with $5 \%$ $\mathrm{CO}_{2}$.

Western blot analysis. The HUVECs were pretreated, as described above, in $10 \mathrm{~cm}$ cell dishes. Cell lysates were prepared by washing twice in cold PBS followed by lysis buffer, containing $50 \mathrm{mM}$ Tris- $\mathrm{HCl}$ (pH 7.4), $10 \mathrm{mM}$ EDTA, 5 mM EGTA, $0.5 \%$ NP40, $1 \%$ Triton X-100 and protease inhibitor (Roche, Mannheim, Germany) and sonication. The cell lysate was centrifuged at $14,000 \mathrm{x}$ g for $10 \mathrm{~min}$ at $4^{\circ} \mathrm{C}$, and the supernatant was discarded. Lysis buffer (150-200 $\mu \mathrm{l})$ was added to each Eppendorf tube. Protein concentration was measured using a Pierce BCA protein assay kit (Thermo Fisher Scientific, Inc. Waltham, MA, USA). Protein samples (40-60 $\mu \mathrm{g}$ ) were mixed with SDS-PAGE loading dye, boiled and loaded onto an SDS-PAGE gel (4-20\%;
Roche). Following transfer of the proteins onto PVDF membranes (Roche), the proteins were blotted with anti-IR (cat. no. sc-57344), anti-phosphorylated (phosphor)-IR (tyrosine; cat. no. sc-17200), anti-IRS-1 (cat. no. SC-8038) and anti-phosphor-IRS-1 (tyrosine; cat. no. sc-17194) antibodies from Santa Cruz Biotechnology, Inc., Dallas, TX, USA), and anti-phosphor-eNOS (serine1177) and total eNOS antibody (cat. no. orb6756) from BD Transduction Laboratories (San Diego, CA, USA) in Tris-buffered saline with Tween, containing $50 \mathrm{mM}$ Tris ( $\mathrm{pH} 7.5), 0.15 \mathrm{M} \mathrm{NaCl}$ and $0.05 \%$ Tween-20, with $5 \%$ fat free milk for $24 \mathrm{~h}$ at $4^{\circ} \mathrm{C}$. Following incubation with antibodies, the membranes were washed and then reacted with horseradish-peroxidase-conjugated IgG (Santa Cruz Biotechnology, Inc.) for $1 \mathrm{~h}$ at $4^{\circ} \mathrm{C}$. The membranes were then treated with ECL reagent (GE Healthcare, Piscataway, NJ, USA) and exposed to X-ray film. $\beta$-actin was used as the protein loading control. Each experiment contained three replicates and was repeated three times.

Analysis of total NO concentrations. Total NO concentrations were determined using a nitrate reduction assay, in which the summation of $\mathrm{NO}_{2}^{-}$and $\mathrm{NO}_{3}{ }^{-}$(24) were measured using a commercially available NO kit (Nanjing Jiancheng Biological Products Co., Ltd., Nianjing, China), according to the manufacturer protocols. This assay was used to quantify the dose effects, as measured by the absorbance at $550 \mathrm{~nm}$. The following equation was used: $\mathrm{NO}(\mu \mathrm{M})=(\mathrm{A}-\mathrm{A} 0) /(\mathrm{As}$ - $\mathrm{A} 0) * \mathrm{Cs} * \mathrm{P}$; where $\mathrm{A}=$ sample absorbance, $\mathrm{A} 0=$ control absorbance As=standard absorbance, $\mathrm{Cs}=$ standard concentration $(100 \mu \mathrm{M}), \mathrm{P}=$ dilution factor. Each experiment contained six replicates and was repeated three times.

Reverse transcription-quantitative polymerase chain reaction analysis (RT-qPCR) of the $m R N A$ levels of ET-1. Following the $24 \mathrm{~h}$ incubation period, total RNA was extracted from the HUVECs using TRIzol reagent (Sigma-Aldrich, St. Louis, MO, USA), according to the manufacturer's protocol. Total RNA $(2 \mu \mathrm{g})$ was subjected to random-primed reverse transcription using SuperScript-2 reverse transcriptase (Invitrogen; Thermo Fisher Scientific, Inc.). qPCR was performed in triplicate using an Applied Biosystem 7900 HT system (Applied Biosystems Life Technologies, Foster City, CA, USA) with $5 \mathrm{ng}$ of cDNA, $1 \mu \mathrm{M}$ of each primer pair and SYBR Green PCR master mix (Roche). RT-qPCR was performed with the following primers: ET-1, forward 5'-AGAGTGTGTCTACTTCTGCCA-3' and reverse CTG CCGTCTAGAA-3'; GAPDH, forward 5'-GGACCTGAC CTGCCGTCTAGAA-3' and reverse 5'-GGTGTCGCTGTT GAAGTCAGAG-3'. Relative mRNA levels were normalized to GAPDH and quantified using the $2^{-\Delta \Delta \mathrm{Cq}}$ method (25). Each experiment contained three replicates and was repeated three times.

Assessment of eNOS activity. Cell lysates were prepared, as described for the western blot analysis. The cell lysates were centrifuged at $14,000 \times \mathrm{g}$ for $10 \mathrm{~min}$ and the supernatant was discarded from the pelleted cells. The activity of eNOS was detected by measuring the conversion of $\left[{ }^{3} \mathrm{H}\right] 1$-arginine to $\left[{ }^{3} \mathrm{H}\right]$ l-citrulline using an eNOS assay kit. (Cayman Chemical 
A

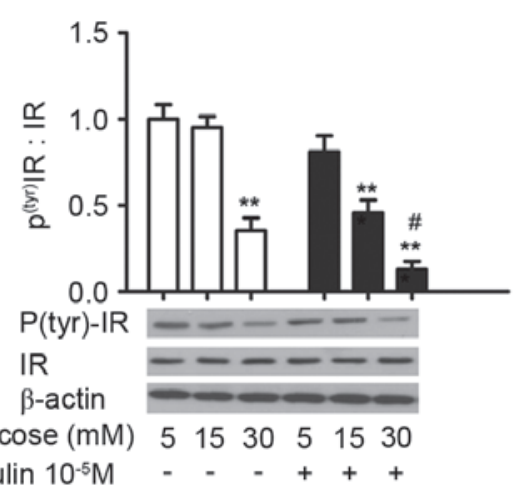

C

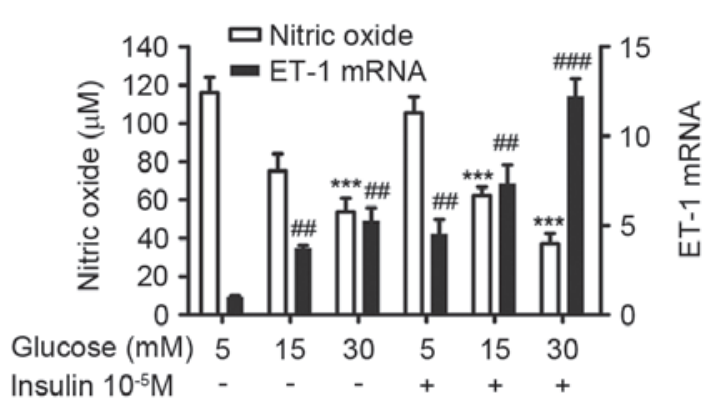

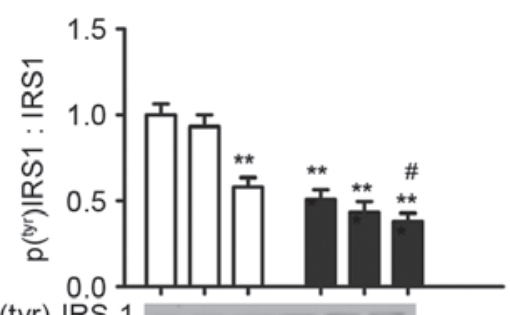

P(tyr)-IRS-1

IRS-1

$\beta$-actin

Glucose (mM) 5153051530

Insulin $10^{-5} \mathrm{M} \quad-\quad-+++$

$\mathbf{E}$

D

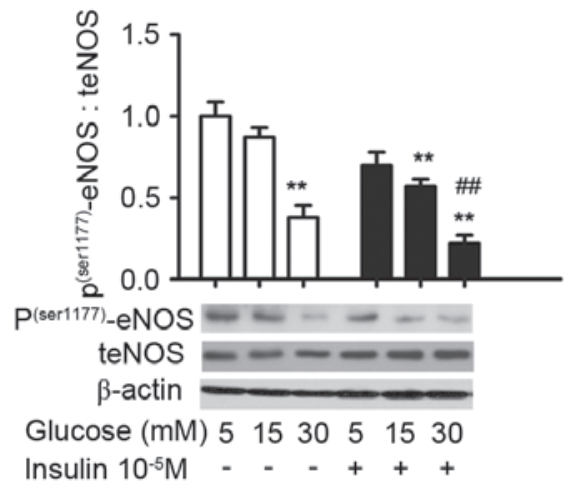

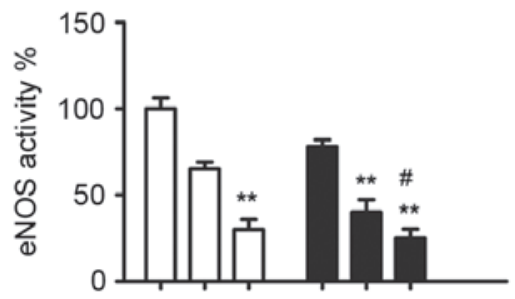

Glucose (mM) $5 \quad 1530 \quad 5 \quad 1530$

Insulin $10^{-5} \mathrm{M}-\mathrm{C}^{-}+++$

Figure 1. High concentrations of glucose and insulin reduce the protein expression levels of phosphor ${ }^{\text {(tyr) }}$ IR and phosphor ${ }^{(\mathrm{tyr})}$-IRS-1, production of NO, protein expression of phosphor ${ }^{(s e r 1177)}$-eNOS and activity of eNOS, and increase the mRNA expression of ET-1 in HUVECs. The HUVECs were treated with indicated concentrations of glucose in the absence (open bars) or presence (filled bars) of insulin $\left(10^{-5} \mathrm{M}\right)$ for $24 \mathrm{~h}$. Western blot analysis of (A) phosphor (tyr) IR and (B) phosphor ${ }^{(\mathrm{tyr})}$ IRS-1. (C) Nitrate reduction assay of NO concentrations and reverse transcription-quantitative polymerase chain reaction analysis of ET-1 mRNA. ${ }^{* * *} \mathrm{P}<0.001$ vs. media containing $5 \mathrm{mM}$ glucose only. The values for ET-1 mRNA in $5 \mathrm{mM}$ glucose without insulin are defined as $1{ }^{\# \#} \mathrm{P}<0.01$ and ${ }^{\# \#} \mathrm{P}<0.001$ vs. 1). (D) Western blot analysis of the protein expression levels of phosphor ${ }^{\text {(ser } 177)}$ eNOS and total eNOS. (E) Assessment of eNOS activity. $(\mathrm{A}, \mathrm{B}, \mathrm{D}$ and $\mathrm{E}){ }^{* *} \mathrm{P}<0.01$ vs. media containing $5 \mathrm{mM}$ glucose only; ${ }^{\# \mathrm{P}}<0.05$, ${ }^{\# \#} \mathrm{P}<0.01$ vs. media containing $30 \mathrm{mM}$ glucose only. The data are presented as the mean \pm standard deviation of three independent experiments. HUVECs, human umbilical vein endothelial cells; phosphor/P, phosphorylated; t, total; IR, insulin receptor; IRS-1, insulin receptor substrate-1; NO, nitric oxide; eNOS, endothelial NO synthase.

Co., Ann Arbor, MI, USA), according to the manufacturer's protocol. The results are expressed as a percentage of the control. Each experiment contained three replicates and was repeated three times.

MTS cell proliferation assays to assess the toxicity of atorvastatin. The cells were seeded in 96 -well plates $(1,000$ cells/well) and were treated with vehicle or with increasing doses of atorvastatin $\left(10^{-6}, 10^{-5}\right.$ and $\left.10^{-4} \mathrm{M}\right)$ for 24 and $48 \mathrm{~h}$ at $37^{\circ} \mathrm{C}$ with $5 \%$ $\mathrm{CO}_{2}$. 3-(4,5-dimethylthiazol-2-yl)-5-(3-carboxymethoxypheny 1)-2-(4-sulfophenyl)-2H-tetrazolium (Promega, Madison, WI, USA; $20 \mu 1 /$ well) was added for $2 \mathrm{~h}$ on the indicated days. Cell proliferation was measured, according to the manufacturer's protocol. Each experiment contained six replicates and was repeated three times.
Statistical analysis. Data are presented as the mean \pm standard deviation. Differences between groups were analyzed using a two-tailed unpaired $t$-test (GraphPad InStat; GraphPad Software, Inc., La Jolla, CA, USA). P $<0.05$ was considered to indicate a statistically significant difference.

\section{Results}

High concentrations of glucose and insulin reduce the protein expression levels of phosphor ${ }^{(t y r)}$-IR and phosphor ${ }^{(t y r)}-I R S-1$, production of NO, protein expression of phosphor(serl177)-eNOS and activity of eNOS, and increase the $m R N A$ level of ET-1 in HUVECs. To establish the effects of high glucose and high insulin concentrations on the function of the HUVECs, the cells were cultured in DMEM containing 5,10 or $30 \mathrm{mM}$ 
A

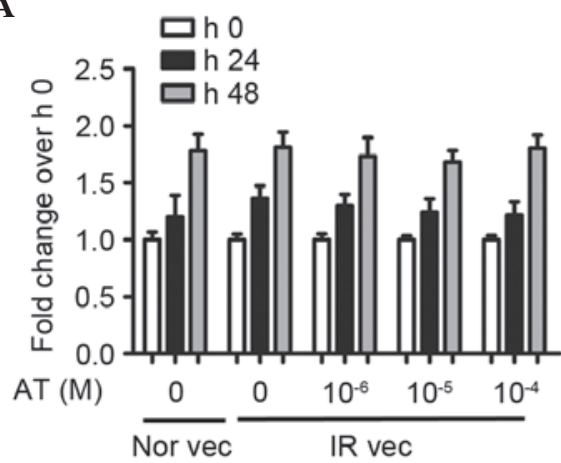

D

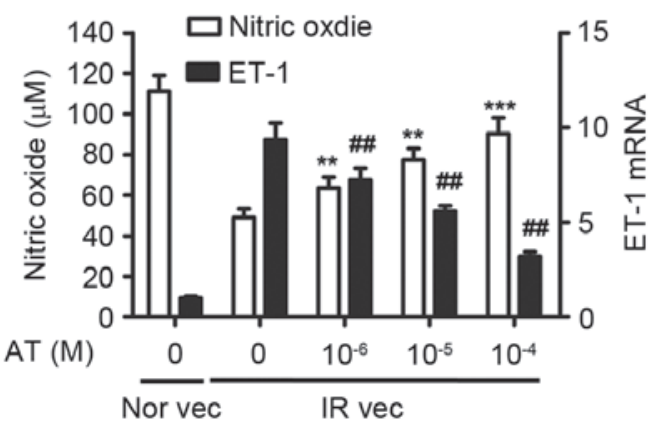

B

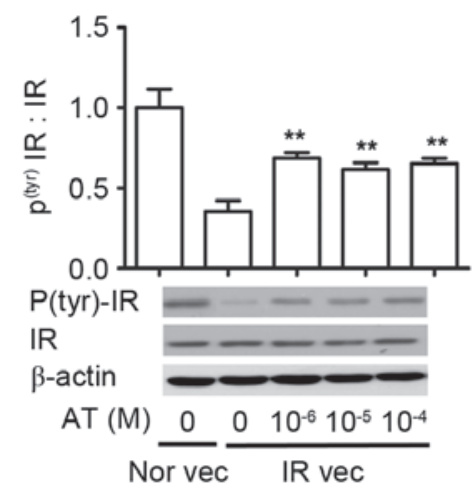

$\mathbf{E}$

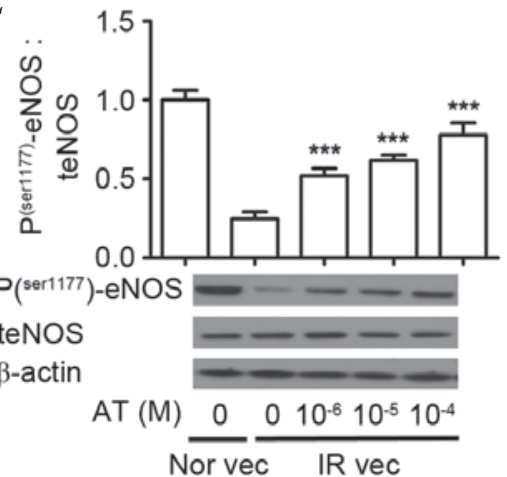

C

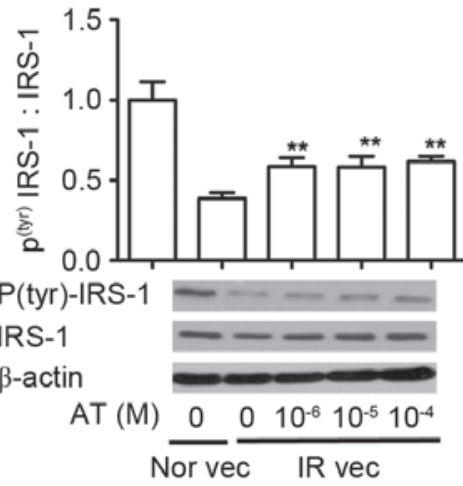

$\mathbf{F}$

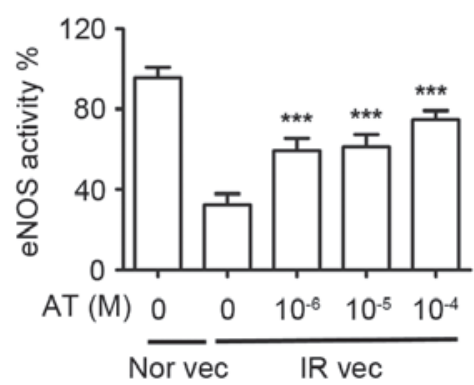

Figure 2. Atorvastatin increases the protein expression of phosphor ${ }^{(\mathrm{tyr})}$-IR and phosphor ${ }^{(\mathrm{tyr})}$-IRS-1, production of NO, protein expression of phosphor $\left({ }^{\text {ser1177}}\right)$-eNOS and activity of eNOS, and downregulates the mRNA level of ET-1 in a dose-dependent manner. The HUVECs were pretreated with 30 mM glucose and $10^{-5} \mathrm{M}$ insulin, and then with atorvastatin $\left(0,10^{-6}, 10^{-5}\right.$ and $\left.10^{-4} \mathrm{M}\right)$. (A) Cell proliferation rates were analyzed using an MTS assay. Western blot analysis of (B) phosphor ${ }^{(\mathrm{tyr})}$ IR and (C) phosphor ${ }^{(\mathrm{tyr})}$ IRS-1. (D) Nitrate reduction assay of NO concentrations and reverse transcription-quantitative polymerase chain reaction analysis of ET-1 mRNA. The values for ET-1 mRNA in the IR vec cells without atorvastatin are defined as 1 . ${ }^{\#} \mathrm{P}<0.01$ vs. 1 . (E) Western blot analysis of phosphor ${ }^{(\text {ser1177) }}$ eNOS and $(\mathrm{F})$ assessment of eNOS activity. (A-F) ${ }^{* *} \mathrm{P}<0.01$ and ${ }^{* * *} \mathrm{P}<0.001$ vs. untreated IR vec. The data are presented as the mean \pm standard deviation of three independent experiments. Nor vec, cells cultured in normal media; IR vec, cells cultured in media containing $30 \mathrm{mM}$ glucose and $10^{-5} \mathrm{M}$ insulin; AT, atorvastatin; HUVECs, human umbilical vein endothelial cells; phosphor/P, phosphorylated; t, total; IR, insulin receptor; IRS-1, insulin receptor substrate-1; NO, nitric oxide; eNOS, endothelial NO synthase.

glucose, either alone or in combination with $10^{-5} \mathrm{M}$ insulin, for $24 \mathrm{~h}$. No differences in cell proliferation or cell morphology were observed between the cells cultured in different concentrations of glucose with or without $10^{-5} \mathrm{M}$ insulin (data not shown). The cells were then treated with insulin at an effective stimulus concentration of $10^{-5} \mathrm{M}$ for $6 \mathrm{~h}$. As shown in Fig. 1A and B, $30 \mathrm{mM}$ glucose significantly decreased the protein levels of phosphor ${ }^{(\mathrm{tyr})}$-IR and phosphor ${ }^{(\mathrm{tyr})}-\mathrm{IRS}-1$ by 60 and $40 \%$, respectively, compared with the level in the cells cultured with $5 \mathrm{mM}$ glucose. Of note, when the cells were treated with the high dose $(30 \mathrm{mM})$ of glucose and $10^{-5} \mathrm{M}$ insulin, there were further decreases in phosphor ${ }^{(\mathrm{tyr})}-\mathrm{IR}$ and phosphor $^{(\mathrm{tyr})}$-IRS-1 $(\mathrm{P}<0.05)$, compared with the cells treated with $30 \mathrm{mM}$ glucose alone. Specifically, the expression of phosphor $^{(\mathrm{tyr})}$-IR was reduced by $60 \%$ and the expression of phosphor $^{(\mathrm{tyr})}$-IRS-1 was reduced by $40 \%$, compared with the level in the cells cultured with $5 \mathrm{mM}$ glucose. The addition of $10^{-5} \mathrm{M}$ insulin alone did not alter the level of phosphor ${ }^{(\mathrm{tyr})}-\mathrm{IR}$, but decreased the level of phosphor ${ }^{(\mathrm{tyr})}$-IRS-1 in the cells cultured with $5 \mathrm{mM}$ glucose.

To confirm that the endothelial dysfunction was induced by high levels of glucose and insulin, the total NO concentration and mRNA level of ET-1 were measured. The protein expression of eNOS was also evaluated. NO production was reduced in the $30 \mathrm{mM}$ glucose group $(53.69 \pm 3.45 \mu \mathrm{M})$ compared with the $5 \mathrm{mM}$ glucose group $(116.17 \pm 4.93 \mu \mathrm{M})$, and $30 \mathrm{mM}$ glucose combined with $10^{-5} \mathrm{M}$ insulin caused a further reduction in NO production $(36.26 \pm 5.24 \mu \mathrm{M}$; Fig. 1C). By contrast, the combination treatment of $30 \mathrm{mM}$ glucose and $10^{-5} \mathrm{M}$ insulin induced an increase of $\sim 13$ fold in the mRNA level of ET-1, compared with the cells treated with $5 \mathrm{mM}$ glucose.

The protein expression of eNOS was further assessed in the present study. As shown in Fig. 1D, glucose and insulin treatment did not alter the expression level of total eNOS, however, higher doses of glucose decreased the protein expression of

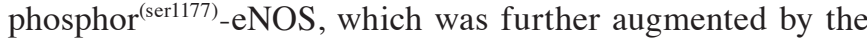
presence of insulin. The phosphorylation level of the cell cultured in $30 \mathrm{mM}$ glucose and $10^{-5} \mathrm{M}$ insulin decreased to $22 \%$ of that of the cells cultured in $5 \mathrm{mM}$ glucose. It was also found that the activity of eNOS altered in parallel with the protein expression of phosphor ${ }^{(\mathrm{ser} 1177)}$-eNOS. The combination of $30 \mathrm{mM}$ glucose and $10^{-5} \mathrm{M}$ insulin caused a significant reduction, to $25 \%$ of th the cells cultured in $5 \mathrm{mM}$ glucose (Fig. 1E).

Atorvastatinincreases the proteinexpressionofphosphor ${ }^{(t y r)}-I R$ and phosphor ${ }^{(t y r)}-I R S-1$, production of $N O$, protein expression of phosphor ${ }^{\text {(ser1177) }}$-eNOS and activity of eNOS, and downregulates the mRNA level of ET-1 in a dose-dependent manner. Prior to examining the effect of atorvastatin on the production of NO, the present study recorded the effect of atorvastatin 
A

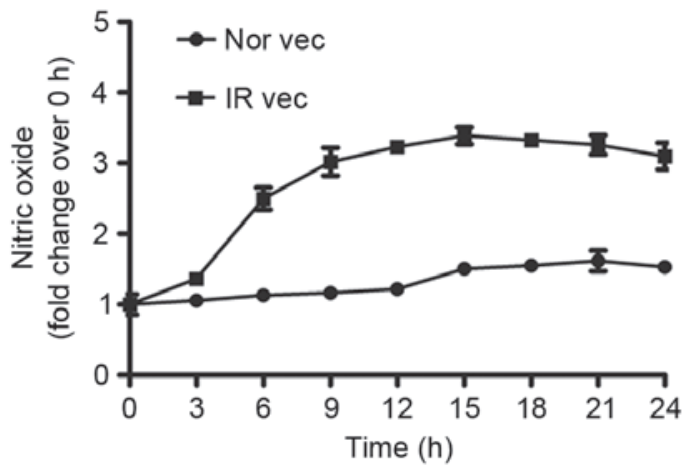

C
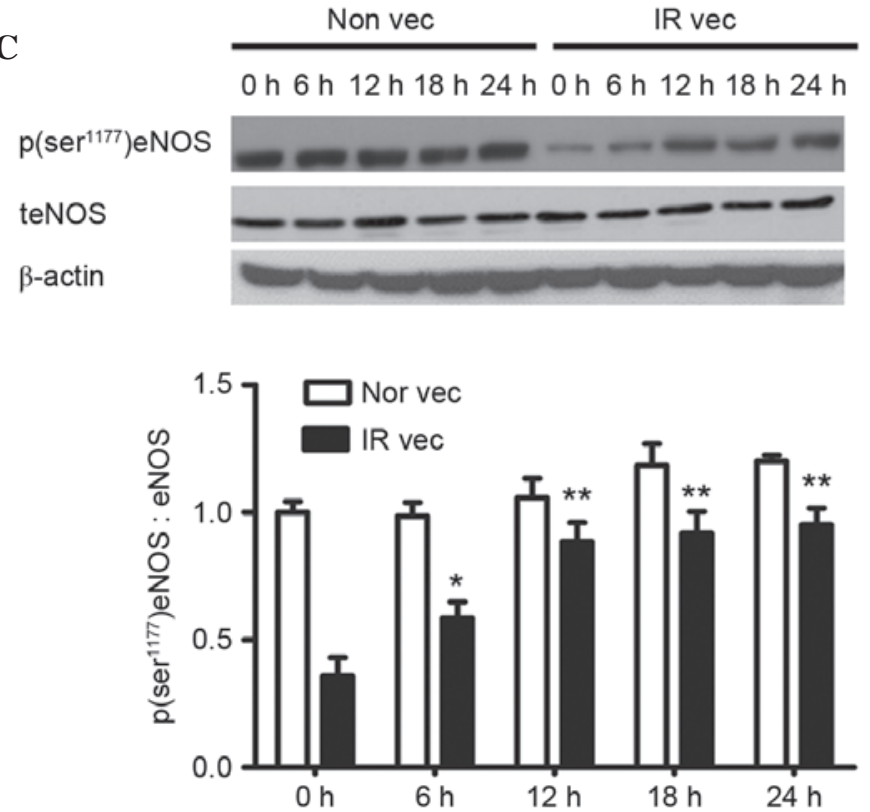

B

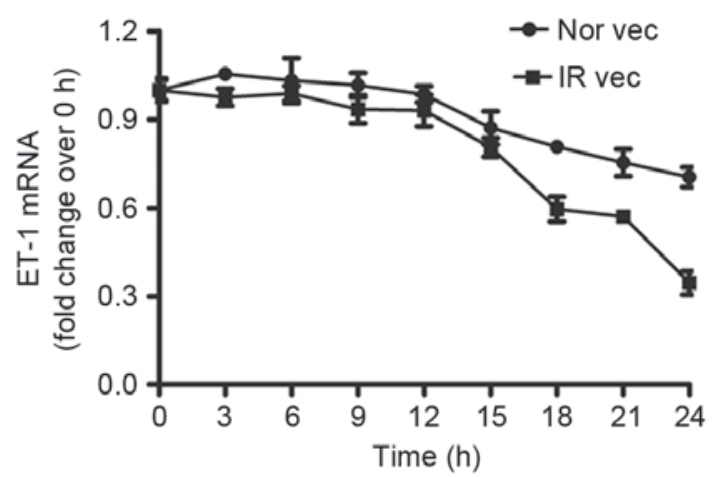

D

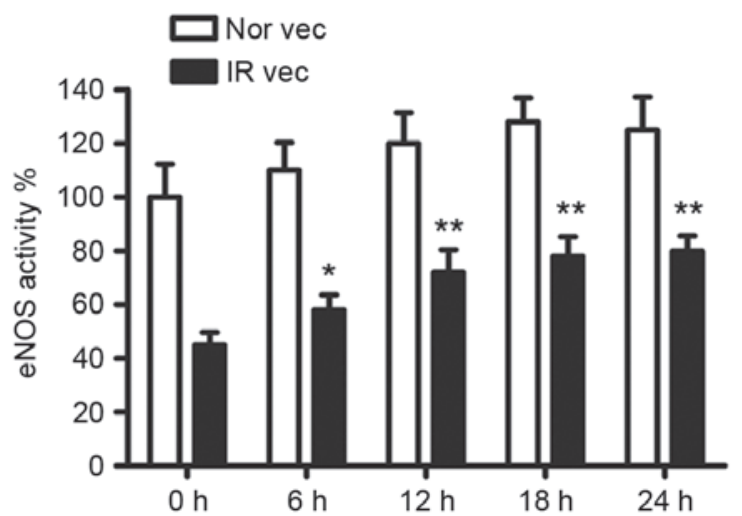

Figure 3. Atorvastatin increases the production of NO, the protein expression of phosphor ${ }^{(\text {ser } 1177)}$-eNOS and the activity of eNOS, and downregulates the mRNA expression of ET-1 in a time-dependent manner. HUVECs were cultured in normal media (Nor vec) and pretreated with $30 \mathrm{mM}$ glucose and $10^{-5} \mathrm{M}$ insulin for $24 \mathrm{~h}$ (IR vec) with or without $10^{-4} \mathrm{M}$ atorvastatin (A) Nitrate reduction assay of $\mathrm{NO}$ concentrations and (B) reverse transcription-quantitative polymerase chain reaction analysis of ET-1 mRNA were performed every $3 \mathrm{~h}$. (C) Western blot analysis of protein levels of phosphor ${ }^{\text {(ser } 1177)}$-eNOS and total eNOS; (D) eNOS activity was measured at the indicated time points. The data are presented as the mean \pm standard deviation of three independent experiments. "P<0.05 and ${ }^{* *} \mathrm{P}<0.01$ vs. IR vec at $0 \mathrm{~h}$. AT, atorvastatin; HUVECs, human umbilical vein endothelial cells; phosphor/P, phosphorylated; t, total; IR, insulin receptor; IRS-1, insulin receptor substrate-1; NO, nitric oxide; eNOS, endothelial NO synthase.

on cell proliferation to assess the toxicity of the atorvastatin. As shown in Fig. 2A, no differences in cell proliferation were observed between the Nor vec, IR vec and IR vec cells incubated with increasing doses of atorvastatin for $48 \mathrm{~h}(\mathrm{P}>0.05)$.

There was an apparent decrease in the insulin-stimulated expression of phosphor ${ }^{(\mathrm{tyr})}$-IR in the IR vec cells, which increased following treatment with atorvastatin. There were significant differences in the expression of phosphor ${ }^{(\mathrm{tyr})}-\mathrm{IR}$ between the Nor vec $(1.00 \pm 0.07)$, untreated IR vec $(0.38 \pm 0.04)$ and IR vec cells treated with increased doses of atorvastatin $\left(10^{-6} \mathrm{M}, 0.68 \pm 0.01 ; 10^{-5} \mathrm{M}, 0.62 \pm 0.03 ; 10^{-4} \mathrm{M}, 0.63 \pm 0.04\right)$. The expression trend of phosphor ${ }^{(\mathrm{tyr})}-\mathrm{IRS}-1$ was similar to phosphor $^{(\mathrm{tyr})}$-IR. There was a significant increase when the IR vec cells were treated with increased doses of atorvastatin $\left(10^{-6} \mathrm{M}, 0.57 \pm 0.05 ; 10^{-5} \mathrm{M}, 0.55 \pm 0.05 ; 10^{-4} \mathrm{M}, 0.60 \pm 0.03\right)$, compared with the untreated IR vec cells $(0.36 \pm 0.04)$. Increasing doses of atorvastatin did not alter the protein expression levels of either phosphor ${ }^{(t y r)}$-IR or phosphor (tyr)-IRS-1 (P>0.05).

The effect of atorvastatin on NO production was also evaluated. As shown in Fig. 2D, atorvastatin significantly increased NO production, compared with the untreated IR vec group, in a dose dependent manner (untreated IR vec, $49.10 \pm 4.23 \mu \mathrm{M} ; 10^{-6} \mathrm{M}, 63.69 \pm 5.19 \mu \mathrm{M} ; 10^{-5} \mathrm{M}, 77.43 \pm 5.56 \mu \mathrm{M}$; $\left.10^{-4} \mathrm{M}, 90.37 \pm 7.92 \mu \mathrm{M}\right)$. By contrast, atorvastatin reduced the mRNA expression of ET-1, compared with the untreated IR vec group. Among the four treatment concentrations, the maximal inhibition rate occurred at the dose of $10^{-4} \mathrm{M}(76 \%)$, however, inhibition was readily detectable at $10^{-6} \mathrm{M}(24 \%)$. Atorvastatin significantly increased the protein expression of

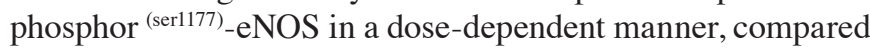
with the untreated IR vec group: Untreated IR vec, $0.24 \pm 0.02$; $\left.10^{-6} \mathrm{M}, 0.52 \pm 0.04 ; 10^{-5} \mathrm{M}, 0.62 \pm 0.03 ; 10^{-4} \mathrm{M}, 0.72 \pm 0.06\right)$. Atorvastatin significantly increased the activity of eNOS, 
A

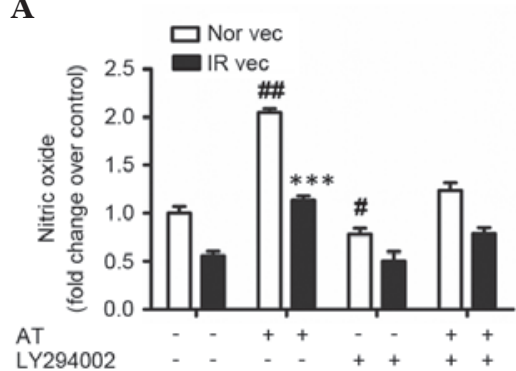

C

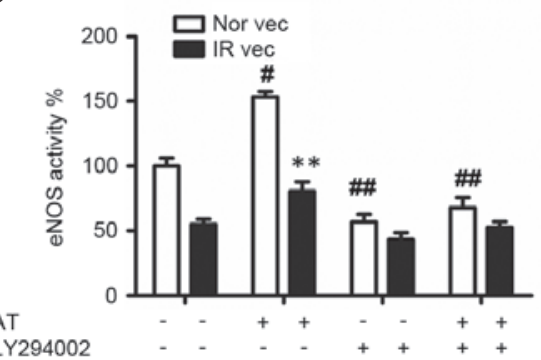

B
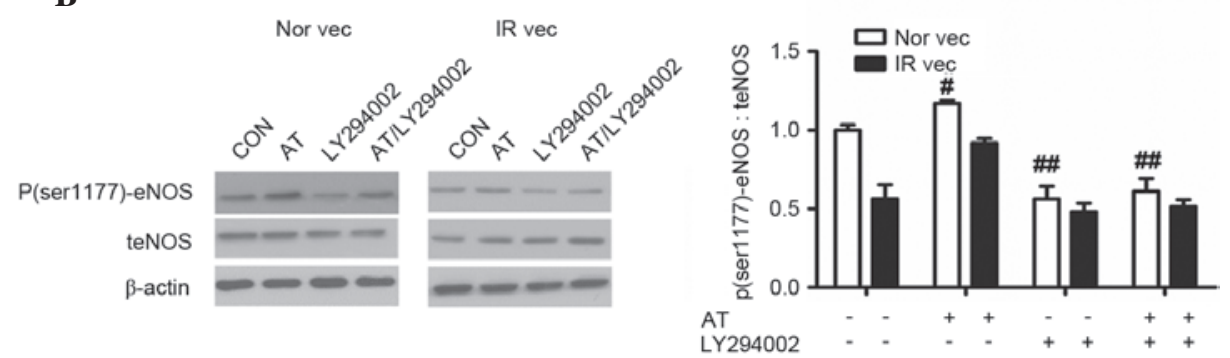

D

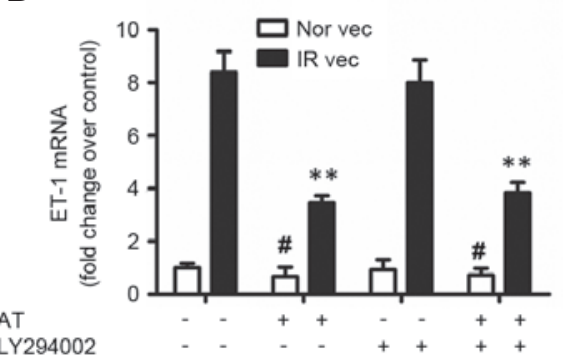

Figure 4. PI3K inhibitor,LY29004, decreases the effect of atorvastatin on NO production, the protein expression of phosphor ${ }^{\text {(ser1177) }}$-eNOS and activity of eNOS, but does not affect the mRNA level of ET-1. HUVECs cultured in normal media (Nor vec) and pretreated with $30 \mathrm{mM}$ glucose and $10^{-5} \mathrm{M}$ insulin

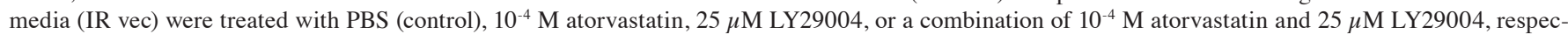
tively. (A) Nitrate reduction assay of NO concentrations; (B) western blot analysis of the protein expression levels of phosphor ${ }^{\text {(ser } 1177)}$ eNOS and total eNOS; (C) assessment of eNOS activity, (D) reverse transcription-quantitative polymerase chain reaction analysis of ET-1 mRNA. The data are presented as the mean \pm standard deviations, ${ }^{*} \mathrm{P}<0.05,{ }^{* *} \mathrm{P}<0.01$ and ${ }^{* * *} \mathrm{P}<0.001$ vs. IR vec treated with $\mathrm{PBS} ;{ }^{\#} \mathrm{P}<0.05$ and ${ }^{\# \#} \mathrm{P}<0.01$ vs. Nor vec treated with PBS. PI3K, phosphatidylinositol 3-kinase; AT, atorvastatin HUVECs, human umbilical vein endothelial cells; phosphor/P, phosphorylated; t, total; IR, insulin receptor; IRS-1, insulin receptor substrate-1; NO, nitric oxide; eNOS, endothelial NO synthase; CON, control.

compared with the untreated IR vec group: Untreated IR vec, $42.33 \pm 4.49 \% ; 10^{-6} \mathrm{M}, 61.67 \pm 5.43 \% ; 10^{-5} \mathrm{M}, 66.14 \pm 4.92 \%$; $10^{-4} \mathrm{M}, 74.67 \pm 3.68 \%$ (Fig. 2D and E).

Atorvastatin increases the production of $N O$, protein expression of phosphor ${ }^{(s e r l 177)}$ - eNOS and activity of eNOS, and downregulates the mRNA expression of ET-1 in a time-dependent manner. To further examine the effect of atorvastatin, the levels of NO produced in the Nor vec and IR vec cells were measured every $3 \mathrm{~h}$. As shown in Fig. 3A, in the IR vec cells, atorvastatin induced the production of $\mathrm{NO}$, the level of which was highest at $9 \mathrm{~h}$ and was maintained during the duration of the asssessment. By contrast no significant alterations were observed in the Nor vec cells. Atorvastatin caused a reduction in the mRNA levels of ET-1 in the Nor vec and IR vec cells. The effect of atorvastatin on the activity of eNOS was also measured. As shown in Fig. 3C, atorvastatin did not alter the expression level of total eNOS in either the Nor vec and IR vec cells during the assessment, however, atorvastatin increased the protein expression of phosphor ${ }^{(\operatorname{ser} 1177)}$-eNOS in a time dependent manner. In addition, eNOS activity in the IR vec cells increased following atorvastatin treatment, but remained at the same level in the Nor vec cells in $24 \mathrm{~h}$.

LY29004, a PI3K inhibitor, decreases the effect of atorvastatin on NO production, protein expression of phosphor (serII77)-eNOS and activity of eNOS, but not the mRNA level of ET-1. To determine whether atorvastatin stimulates eNOS activation in a PI3K/Akt/eNOS-dependent manner, the cells were treated with the PI3K inhibitor, LY294002. As shown in Fig. 4A, atorvastatin induced an increase in the production of
NO in the Nor vec and IR vec cells. This effect was reduced by LY294002 $(\mathrm{P}<0.05)$. Similarly, the effects of atorvastatin on the protein expression of phosphor (ser1177)-eNOS and activity of eNOS were reduced by LY294002 in the Nor vec and IR vec cells $(\mathrm{P}<0.05$; Fig. 4B and $\mathrm{C})$. However, the redutcion observed in the mRNA expression of ET-1 was not affected by LY294002 (P>0.05).

\section{Discussion}

Impairment of vascular endothelial cell structure and function is a common pathological basis of cardiovascular disease. The predominant factors, which lead to vascular endothelial dysfunction include dyslipidemia, impairment of endothelium-dependent vasodilation and inflammation (1). Insulin resistance, the early stage of type 2 diabetes, is frequently associated with endothelial dysfunction as an early predictor of atherosclerosis and risk of cardiovascular disease $(13,26)$. However, the mechanism of interaction between insulin resistance and endothelial dysfunction remains to be elucidated. Atorvastatin is a vessel protective drug, which has been confirmed to protect endothelial function by increasing NO production, and reducing circulating levels of interleukin (IL)- 6 and tumor necrosis-factor (TNF)- $\alpha$ independent of changes in plasma cholesterol $(27,28)$. In the present study, an insulin resistant-endothelial dysfunction model was established by treating the HUVECs with high concentrations of glucose and insulin for $24 \mathrm{~h}$. Compared with normal culture media, high concentrations of glucose and insulin interfered with insulin signaling by decreasing insulin-stimulated phosphor ${ }^{(\mathrm{tyr})}$-IR and downstream IRS-1. This result is consistent with previous reports that hyperglycemia can induce insulin resis- 
tance by inhibiting phosphor ${ }^{(\mathrm{tyr})}$-IRS-1, which in turn negatively regulates its function $(29,30)$.

In individuals with insulin-resistance, the impairment of insulin signal transduction via the PI3K pathway can downregulate the level of phosphor ${ }^{\left(s^{2} 1177\right)}$-eNOS and decrease NO production (31). In the present study, impairment of endothelial insulin signaling was accompanied by a reduction in tyrosine phosphorylation of the insulin receptor substrate. Previous reports have indicated that the expression of TNF- $\alpha$ is significantly increased in insulin resistance by decreasing the tyrosine kinase activity of the insulin receptor $(32,33)$. In addition, TNF- $\alpha$ induces the activation of NAD(P)H oxidase, leading to endothelial dysfunction with increased ET-1 availability $(34,35)$. Thus, the present study hypothesized that superphysiological concentrations of insulin and glucose increase the expression of ET-1 through the downstream effects of the upregulation of $\mathrm{TNF}-\alpha$ on NAD(P)H oxidase and superoxide anion production. The effects of atorvastatin on insulin sensitivity have been reported in previous years. Wong et al reported that atorvastatin induced insulin sensitization in Zucker lean and fatty rats (36). Atorvastatin also reverses the reduction of phosphor ${ }^{\text {(tyr) }}$-IR and phosphor ${ }^{(\mathrm{tyr})}$-IRS-1 in animal models of insulin resistance or impairment of insulin signaling $(37,38)$. However, the function of atorvastatin on insulin sensitivity in insulin resistant-endothelial dysfunction cell models has not been reported. The data obtained in the present study are the first, to the best of our knowledge, to show that atorvastatin reversed the inhibition of phosphor ${ }^{\text {(tyr) }}$-IR and phosphor ${ }^{\text {(tyr) }}$-IRS-1 induced by high glucose in combination with high insulin. In addition, atorvastatin increased the production of NO and dow-regulated the expression of ET-1 in a dose and time dependent manner.

In the present study, the PI3K inhibitor, Ly294002, was used. The production of NO, protein expression of phosphor (ser177)-eNOS and activity of eNOS were significantly decreased when the cells were treated with LY294002, which indicated that PI3K was a specific upstream effector to phosphorylate the eNOS on ser1177. In conclusion, the present study provided the first evidence, to the best of our knowledge, that a high concentration of glucose in combination with a high concentration of insulin stimulated endothelial insulin resistance in vascular endothelial cells. In addition, atorvastatin ameliorated these effects, primarily via the PI3K/Akt/eNOS pathway. These findings provide further evidence that atorvastatin is useful for patients with insulin resistance.

\section{Acknowledgements}

This study was supported by grants from the Scientific Research Project of the Department of Finance, Jilin Province, China (grant no. 3D512W143428). The authors would like to thank Dr. William Orr, Department of Pathology, University of Manitoba, Canada for his assistance in manuscript preparation.

\section{References}

1. Versari D, Daghini E, Virdis A, Ghiadoni L and Taddei S: Endothelial dysfunction as a target for prevention of cardiovascular disease. Diabetes Care 32 (Suppl 2): S314-S321, 2009.

2. Cersosimo E and DeFronzo RA: Insulin resistance and endothelial dysfunction: The road map to cardiovascular diseases. Diabetes Metab Res Rev 22: 423-436, 2006.
3. Davignon J and Ganz P: Role of endothelial dysfunction in atherosclerosis. Circulation 109 (23 Suppl 1): IIII27-III32, 2004.

4. Reaven GM: Banting lecture 1988. Role of insulin resistance in human disease. Diabetes 37: 1595-1607, 1988.

5. Wheatcroft SB, Williams IL, Shah AM and Kearney MT: Pathophysiological implications of insulin resistance on vascular endothelial function. Diabetic Med 20: 255-268, 2003.

6. Heitzer T, Schlinzig T, Krohn K, Meinertz T and Münzel T: Endothelial dysfunction, oxidative stress and risk of cardiovascular events in patients with coronary artery disease. Circulation 104: 2673-2678, 2001.

7. Ginsberg HN: Insulin resistance and cardiovascular disease. J Clin Invest 106: 453-458, 2000

8. Kubota T, Kubota N, Kumagai H, Yamaguchi S, Kozono H, Takahashi T, Inoue M, Itoh S, Takamoto I, Sasako T, et al: Impaired insulin signaling in endothelial cells reduces insulin-induced glucose uptake by skeletal muscle. Cell Metab 13: 294-307, 2011.

9. Rask-Madsen C, Li Q, Freund B, Feather D, Abramov R, Wu IH, Chen K, Yamamoto-Hiraoka J, Goldenbogen J, Sotiropoulos KB, et al: Loss of insulin signaling in vascular endothelial cells accelerates atherosclerosis in apolipoprotein E null mice. Cell Metab 11: 379-389, 2010.

10. Kim F, Pham M, Maloney E, Rizzo NO, Morton GJ, Wisse BE, Kirk EA, Chait A and Schwartz MW: Vascular inflammation, insulin resistance and reduced nitric oxide production precede the onset of peripheral insulin resistance, Arterioscler Thromb Vasc Biol 28: 1982-1988, 2008.

11. Okamoto H, Obici S, Accili D and Rossetti L: Restoration of liver insulin signaling in Insr knockout mice fails to normalize hepatic insulin action. J Clin Invest 115: 1314-1322, 2005.

12. Garcia Soriano F, Virág L, Jagtap P, Szabó E, Mabley JG, Liaudet L, Marton A, Hoyt DG, Murthy KG, Salzman AL, et al: Diabetic endothelial dysfunction: The role of poly(ADP-ribose) polymerase activation, Nat Med 7: 108-113, 2001.

13. Rask-Madsen C and King GL: Mechanisms of disease: Endothelial dysfunction in insulin resistance and diabetes. Nat Clin Pract Endocrinol Metab 3: 46-56, 2007.

14. Arcaro G, Cretti A, Balzano S, Lechi A, Muggeo M, Bonora E and Bonadonna RC: Insulin causes endothelial dysfunction in humans sites and mechanisms. Circulation 105: 576-582, 2002.

15. Burén J, Liu HX, Lauritz J and Eriksson JW: High glucose and insulin in combination cause insulin receptor substrate- 1 and-2 depletion and protein kinase $\mathrm{B}$ desensitisation in primary cultured rat adipocytes: Possible implications for insulin resistance in type 2 diabetes. Eur J Endocrinol 148: 157-167, 2003.

16. Gelosa P, Cimino M, Pignieri A, Tremoli E, Guerrini U and Sironi L: The role of HMG-CoA reductase inhibition in endothelial dysfunction and inflammation. Vasc Health Risk Manag 3: 567-577, 2007.

17. Durazzo AE, Machado FS, Ikeoka DT, De Bernoche C, Monachini MC, Puech-Leão P and Caramelli B: Reduction in cardiovascular events after vascular surgery with atorvastatin: A randomized trial. J Vasc Surg 39: 967-975; discussion 975-976, 2004.

18. Chello M, Goffredo C, Patti G, Candura D, Melfi R, Mastrobuoni S, Di Sciascio G and Covino E: Effects of atorvastatin on arterial endothelial function in coronary bypass surgery. Eur J Cardiothorac Surg 28: 805-810, 2005.

19. Cantley LC: The phosphoinositide 3-kinase pathway. Science 296: 1655-1657, 2002.

20. Dilaveris P, Giannopoulos G, Riga M, Synetos A and Stefanadis C: Beneficial effects of statins on endothelial dysfunction and vascular stiffness. Curr Vasc Pharmacol 5: 227-237, 2007.

21. Mahmoud MF, El-Nagar $M$ and El-Bassossy HM: Anti-inflammatory effect of atorvastatin on vascular reactivity and insulin resistance in fructose fed rats. Arch Pharm Res 35: 155-162, 2012.

22. Calisto KL, B. Carvalho B, Ropelle ER, Mittestainer FC, Camacho AC, Guadagnini D, Carvalheira JB and Saad MJ: Atorvastatin improves survival in septic rats: Effect on tissue inflammatory pathway and on insulin signaling. PLoS One 5 e14232, 2010

23. Li X, Shi Y, Wei Y, Ma X, Li Y and Li R: Altered expression profiles of microRNAs upon arsenic exposure of human umbilical vein endothelial cells. Environ Toxicol Pharmacol 34: 381-387, 2012.

24. Schmidt RJ and Baylis C: Total nitric oxide production is low in patients with chronic renal disease. Kidney Int 58: 1261-1266, 2000.

25. Livak KJ and Schmittgen TD: Analysis of relative gene expression data using real-time quantitative PCR and the 2(-Delta Delta C(T)) Method. Methods 25: 402-408, 2001. 
26. Lebovitz HE: Insulin resistance-a common link between type 2 diabetes and cardiovascular disease. Diabetes Obes Metab 8: 237-249, 2006

27. Tousoulis D, Antoniades C, Katsi V, Bosinakou E, Kotsopoulou M, Tsioufis $C$ and Stefanadis C: The impact of early administration of low-dose atorvastatin treatment on inflammatory process, in patients with unstable angina and low cholesterol level. Int J Cardiol 109: 48-52, 2006.

28. Tousoulis D, Charakida M, Stefanadi E, Siasos G, Latsios G and Stefanadis C: Statins in heart failure. Beyond the lipid lowering effect. Int J Cardiol 115: 144-150, 2007.

29. Ozcan U, Cao Q, Yilmaz E, Lee AH, Iwakoshi NN, Ozdelen E, Tuncman G, Görgün C, Glimcher LH and Hotamisligil GS: Endoplasmic reticulum stress links obesity, insulin action, and type 2 diabetes. Science 306: 457-461, 2004.

30. Hribal ML, Perego L, Lovari S, Andreozzi F, Menghini R, Perego C, Finzi G, Usellini L, Placidi C, Capella C, et al: Chronic hyperglycemia impairs insulin secretion by affecting insulin receptor expression, splicing and signaling in RIN beta cell line and human islets of Langerhans. FASEB J 17: 1340-1342, 2003.

31. Muniyappa R and Quon MJ: Insulin action and insulin resistance in vascular endothelium. Curr Opin Clin Nutr Metab Care 10: 523-530, 2007.

32. Gonzalez-Gay MA, De Matias JM, Gonzalez-Juanatey C, Garcia-Porrua C, Sanchez-Andrade A, Martin J and Llorca J: Anti-tumor necrosis factor-alpha blockade improves insulin resistance in patients with rheumatoid arthritis. Clin Exp Rheumatol 24: 83-86, 2006.
33. De Taeye BM, Novitskaya T, McGuinness OP, Gleaves L, Medda M, Covington JW and Vaughan DE: Macrophage TNF-alpha contributes to insulin resistance and hepatic steatosis in diet-induced obesity. Am J Physiol Endocrinol Metab 293: E713-E725, 2007.

34. López-Sepúlveda R, Gómez-Guzmán M, Zarzuelo MJ, Romero M, Sánchez M, Quintela AM, Galindo P, O'Valle F, Tamargo J, Pérez-Vizcaíno F, et al: Red wine polyphenols prevent endothelial dysfunction induced by endothelin-1 in rat aorta: Role of NADPH oxidase. Clin Sci (Lond) 120: 321-333, 2011.

35. Zhang H, Zhang J, Ungvari Z and Zhang C: Resveratrol Improves endothelial function: Role of TNF $\{$ alpha\} and vascular oxidative stress. Arterioscler Thromb Vasc Biol 29: 1164-1171, 2009.

36. Wong V, Stavar L, Szeto L, Uffelman K, Wang CH, Fantus IG and Lewis GF: Atorvastatin induces insulin sensitization in Zucker lean and fatty rats. Atherosclerosis 184: 348-355, 2006.

37. Lalli CA, Pauli JR, Prada PO, Cintra DE, Ropelle ER, Velloso LA and Saad MJ: Statin modulates insulin signaling and insulin resistance in liver and muscle of rats fed a high-fat diet. Metabolism 57: 57-65, 2008

38. Calisto KL, Carvalho Bde M, Ropelle ER, Mittestainer FC, Camacho AC, Guadagnini D, Carvalheira JB and Saad MJ: Atorvastatin improves survival in septic rats: Effect on tissue inflammatory pathway and on insulin signaling. PloS One 5: e14232, 2010 